\title{
Mapping of Quantitative Trait Loci for Leaf Rust Resistance in the Wheat Population Ning7840 $\times$ Clark
}

Chunlian Li and Zhonghua Wang, College of Agronomy, Northwest A\&F University, Yangling, Shaanxi, China; Chunxin Li, Wheat Institute, Henan Academy of Agricultural Science, Zhengzhou, 450002, China; Robert Bowden and Guihua Bai, ${ }^{\dagger}$ Hard Winter Wheat Genetics Research Unit, USDA-ARS, Manhattan, KS; Chunlian Li, Chunxin Li, and Zhenqi Su, Agronomy Department, Kansas State University, Manhattan, KS; and Brett F. Carver, Department of Plant and Soil Sciences, Oklahoma State University, Stillwater, OK 74078

\begin{abstract}
Leaf rust, caused by Puccinia triticina, is an important fungal disease of wheat (Triticum aestivum L.) and causes significant yield losses worldwide. To determine quantitative trait loci (QTLs) responsible for leaf rust resistance, a recombinant inbred line (RIL) population developed from a cross of Ning7840 $\times$ Clark was evaluated for leaf rust severity, and was genotyped for single nucleotide polymorphisms (SNPs) using 9K Illumina chips, and with simple sequence repeat (SSR) markers. Two major QTLs on chromosome arms 7DS and 3BS, and two minor QTLs on chromosomes $5 \mathrm{AS}$ and $6 \mathrm{AS}$ showed a significant effect on leaf rust severity. The

7DS QTL from Ning7840 and the 3BS QTL from Clark explained, respectively, about $35 \%$ and $18 \%$ of the phenotypic variation for leaf rust resistance. The QTL on 7DS was confirmed to be Lr34. The QTL on 3BS, QLr.hwwg$3 B .1$, was associated with adult plant resistance and was provisionally identified as Lr74. QLr.hwwg-5AS and QLr.hwwg-6AS from Ning7840 and Clark, respectively, may correspond to previously described QTLs. Lr34, QLr.hwwg-3BS.1, and QLr.hwwg-6AS had an additive effect on leaf rust severity. RILs with all three favorable alleles showed the highest resistance to leaf rust and the RILs with none of them showed the lowest resistance.
\end{abstract}

Leaf rust, caused by Puccinia triticina Erikss., is an important fungal disease of bread wheat (Triticum aestivum L.) and causes significant yield losses in wheat worldwide (Bolton et al. 2008). Typical leaf rust symptoms are orange-brown pustules that erupt on wheat leaf surfaces and result in reduced photosynthetic activity in infected leaves. Leaf rust damage occurs more often where dews are frequent and temperature is mild from plant jointing to flowering stages (Kumar 2014; Moschini and Perez 1999).

Deployment of resistant cultivars is the most economical and desirable approach for disease control (Bolton et al. 2008; McIntosh et al. 1995). However, the leaf rust pathogen population typically overcomes resistant cultivars as virulent races are selected by resistance genes in the new cultivars (Kolmer and Hughes 2016). Pyramiding multiple resistance genes or quantitative trait loci (QTLs) in a cultivar can improve resistance durability. DNA markers tightly linked to these genes are essential to this pyramiding process. QTL mapping is a powerful tool for locating genes in a chromosome region from a new source and identifying closely linked markers to these genes for marker-assisted selection. To date, more than 70 leaf rust resistance genes or QTLs have been identified in wheat and its relatives ( $\mathrm{Li}$ et al. 2014; McIntosh et al. 2015; Rosewarne et al. 2008). Several racespecific leaf rust resistance genes have been cloned and found to encode NBS-LRR types of resistance gene proteins (Feuillet et al. 2003; Huang et al. 2003). Most genes of this type are effective throughout the life of the plant and are often called all-stage resistance, or seedling resistance because they can be detected at the seedling growth stage.

In contrast, adult plant resistance (APR) is difficult or impossible to detect at the seedling stage. It typically becomes increasingly effective as the plant approaches the reproductive stage. Although some APR genes are race-specific, such as Lr12 (Singh and Bowden 2011), others are race-

${ }^{\dagger}$ Corresponding author: Guihua Bai; E-mail: guihua.bai@ ars.usda.gov

Accepted for publication 2 August 2017.

This article is in the public domain and not copyrightable. It may be freely reprinted with customary crediting of the source. The American Phytopathological Society, 2017. nonspecific, such as $L r 34, L r 46, L r 67, L r 68, Y r 36$, and $S r 2$ (Ellis et al. 2014; Herrera-Foessel et al. 2012; Singh et al. 2011). The racenonspecific group often exhibits pleiotropic resistance effects on stem rust, stripe rust, leaf rust, and powdery mildew and often provides long-lasting, durable resistance (Ellis et al. 2014). The race-nonspecific APR genes Lr34 (Krattinger et al. 2009), Lr67 (Moore et al. 2015), and Yr36 (Fu et al. 2009) have been cloned and found to encode a putative $\mathrm{ABC}$ transporter, a hexose transporter, and a kinase-START gene, respectively. These novel classes of resistance genes are thought to confer novel mechanisms of resistance that result in pleiotropism and durability. One drawback of this type of gene is that resistance is only partial, so they need to be used in combinations (Singh et al. 2011). Additional sources of durable APR are needed to increase the effectiveness and durability of gene combinations.

Li and Bai (2009) described a QTL, Qlr.pser.1BL, for APR to leaf rust in the Chinese wheat cultivar Ning 7840 in a cross with the variety Chokwang. The resistance was associated with a lesion mimic phenotype $(\mathrm{lm})$ on chromosome 1BL and explained $61 \%$ of the phenotypic variation in two greenhouse experiments. In a subsequent study, $\mathrm{Li}$ et al. (2012) reported that Ning7840 also contains APR gene Lr34. Additive effects were observed for $l m$ and $L r 34$ on leaf rust severity in the greenhouse. Lesion mimic phenotypes result in hypersensitive-like necrotic lesion in the absence of pathogen challenge. In several systems, they have been associated with upregulated defense pathways and enhanced resistance to biotrophs and facultative pathogens (McGrann et al. 2015; Wu et al. 2008). Li et al. (2012) suggested that $l m$ might be a unique source of APR to leaf rust in wheat.

In the current study, we took advantage of an existing RIL population of Ning7840 crossed with the soft red winter wheat Clark to test the effect of $l m$ under field conditions. It also provided an opportunity to map the intermediate level of resistance to leaf rust that occurs in Clark. The specific objectives of this research were to identify QTLs and quantify their effects on leaf rust reaction in Ning7840 and Clark, and to determine possible relationships between identified QTLs and known genes for leaf rust resistance.

\section{Materials and Methods}

Plant materials and evaluation of resistance to leaf rust. A population of $127 \mathrm{~F}_{12}$ recombinant inbred lines (RILs) was developed from the cross Ning7840 $\times$ Clark by single-seed descent. Ning7840 
is a Chinese hard red cultivar with the pedigree of (Aurora $\times$ Anhui11) $\times$ Sumai3. It has relatively low yield potential but is highly resistant to rust pathogens and Fusarium graminearum (Bai et al. 1999). Sumai3 is one of the Chinese accessions that carry Lr34 for APR to leaf rust, and Ning7840 carries $L r 34$ from Sumai3 (Li et al. 2012). Ning 7840 also carries the $1 B / 1 R$ translocation carrying Lr26 (Li and Bai 2009). Clark is a soft red winter wheat cultivar developed at Purdue University, IN, USA, and released in 1987 with a high yield potential and resistance to several diseases including rusts (Ohm et al. 1988).

To identify an isolate that can be used to evaluate adult plant resistance only, seedlings of both parents and checks with known leaf rust resistance genes were inoculated with different isolates. Clark, Ning7840, Chinese Spring (carrying Lr31), Gatcher $(L r 27+L r 31)$, and the Chinese Spring/Hope 3B substitution line $(\operatorname{Lr} 27+L r 31)$ were grown in a growth chamber at $18^{\circ} \mathrm{C}$ for 10 days. Seedlings were lightly inoculated with a $1 \%(\mathrm{v} / \mathrm{v})$ suspension of urediniospores in Soltrol 170 isoparaffin oil (Chevron Phillips, The Woodlands, TX) using a rust inoculation atomizer (Tallgrass Solutions, Inc., Manhattan, KS). Seedlings were incubated for $14 \mathrm{~h}$ in the dark at $100 \%$ humidity in an I-36DL dew formation chamber (Percival Scientific, Perry, IA) and then incubated 11 days at $18^{\circ} \mathrm{C}$ with a $16-\mathrm{h}$ photoperiod in a growth chamber before rust note was taken. Infection types (ITs) and race typing on differential sets were as described by Long and Kolmer (1989) as modified by Kolmer and Hughes (2016). The rust cultures used for seedling inoculation included race BBBDB (virulent to $L r 14 a$ ), MCDSB (virulent to $L r 1, L r 3, L r 26, L r 17, L r B, L r 10, L r 14 a$ ), and race PNMRJ (virulent to $L r 1, L r 2 c, L r 3, L r 9, L r 24, L r 3 k a, L r 30, L r B, L r 10, L r 28, L r 39$ ), which represented major isolates from the central Great Plains.

Leaf rust resistance was evaluated in the field experiments at Stillwater $\left(36^{\circ} 9^{\prime} \mathrm{N}, 97^{\circ} 05^{\prime} \mathrm{W}\right)$ and Lahoma $\left(36^{\circ} 22^{\prime} \mathrm{N}, 98^{\circ} 00^{\prime} \mathrm{W}\right)$, OK, USA, in 2002. The two locations are about $120 \mathrm{~km}$ apart, and the population was planted at Stillwater in 24 October and at Lahoma in 17 October 2001. To manage experimental errors in the large experiments, the mapping population, two parents and one susceptible check (Chisholm) that has no known leaf rust resistance gene were planted using a replicates-in-sets design with three replications, following Carver and Rayburn (1994). In brief, 127 RILs were divided into four sets. In each set, entries (Chisholm, two parents, and 32 RILs) were arranged as a randomized complete-block design with three replications. A two-row plot of $1.4 \mathrm{~m}^{2}$ was planted for each entry at a seeding rate of $58 \mathrm{~kg} / \mathrm{ha}$. Following natural field infection, leaf rust severity on flag leaves was visually estimated on a percentage scale (Peterson et al. 1948) during kernel filling stage (Feekes growth stages 10.54 to 11.1 ) when rust coverage on flag leaves of Chisholm and highly susceptible RILs reached $80 \%$ before flag leaves started drying (May 15 in Lohoma and May 18 in Stillwater). The year 2002 was a routine year for leaf rust. Rust rating used for QTL analysis was an average rating from three replications for each RIL at each location.

DNA extraction and marker analysis. Genomic DNA isolation from both the parents and RILs, and the polymerase chain reactions (PCRs) for the SSRs were conducted using previously described protocols (Zhang et al. 2010). PCR amplicons were separated using an ABI Prism 3730 DNA Analyzer (Applied Biosystems, Foster City, $\mathrm{CA}$ ), and the data were scored using GeneMarker version 1.6 (Soft Genetics LLC, State College, PA).

SNP genotyping was performed for both parents and RILs using the Infinium iSelect SNP genotyping assays with 9,000 wheat SNPs (Illumina Inc., San Diego, CA). The assay was designed under the protocol developed by the International Wheat SNP Consortium (Cavanagh et al. 2013). The genotyping assays were conducted at the USDA Small Grains Genotyping Laboratory at Fargo, ND, and SNPs were called using GenomeStudio v2011.1 software (Illumina Inc.). Altogether 2,404 SNP markers, 366 polymorphic SSR markers, and two linked markers, Lr34exon11-KASP (Bernardo et al. 2015) for gene Lr34 and Umn10 (Liu et al. 2008) for Fhbl, were used to construct the linkage map. Lr34exon11-KASP is a KASP (Kompetitive allele specific PCR) marker that detects single nucleotide polymorphisms using a fluorescencebased technology.
Linkage map construction and QTL detection. The linkage map was constructed using 9K wheat SNP and SSR marker data from the Ning7840 $\times$ Clark $\mathrm{F}_{8-12}$ RILs. Map construction used the MAP functionality in software QTL IciMapping 3.2 (Li et al. 2016; Wang et al. 2012). The linkage map was constructed using the Kosambi mapping function (Kosambi 1943) and a minimum LOD value of 6.0. QTL mapping was performed using inclusive composite interval mapping of additive (ICIM-ADD) functionality. Additive QTLs were detected using a $1.0 \mathrm{cM}$ step-in scan. The probability used in stepwise regression was 0.001 , and the LOD significance threshold was determined using permutation tests (1,000 times) with a Type I error threshold of 0.05 .

\section{Results}

Leaf rust reaction. In seedling assays, Ning7840 had ITs of ;1-, 3; and ; 1 to races BBBDB, MCDSB, and PNMRJ, respectively (Table 1). The results were consistent with the known presence of $L r 26$ ( $\mathrm{Li}$ and Bai 2009) plus an additional gene of small effect. Clark had ITs of 3+, 3+, and 3; to BBBDB, MCDSB, and PNMRJ, respectively. BBBDB was avirulent (IT ;3) to $L r 27+L r 31$ in the Chinese Spring/Hope $3 \mathrm{~B}$ substitution line and virulent (IT $3+$ ) to Clark, and thus, Clark does not carry $L r 27+L r 31$. BBBDB is avirulent to all resistance genes in the differential sets except Lr14a. Clark showed resistance to PNMRJ, which is avirulent on Lr14a. Therefore, we postulated that Clark carries only $L r 14 a$ for all-stage resistance.

In both the Oklahoma locations, Ning 7840 exhibited significantly lower leaf rust severity (12.7\% in Stillwater and $12.3 \%$ in Lahoma) than Clark (46.0\% in Stillwater and $24.3 \%$ in Lahoma) (Table 2, Fig. 1). The distribution of leaf rust severity scores among RILs was continuous with obvious transgressive segregation, suggesting both parents contributed leaf rust resistance alleles in this population. The RIL population had mean leaf rust severity of $45.8 \%$ in Stillwater and $53.5 \%$ in Lahoma, varying from 1.2 to $93.3 \%$ in Stillwater and 2.0 to $99.0 \%$ in Lahoma. The correction in rust severity was high between locations $(\mathrm{r}=0.91)$.

Genetic map and additive QTLs for leaf rust resistance. Among 2,772 markers used to construct map, 2,708 markers including 2,400 SNPs, and 308 SSRs or STS (sequence-tagged site) markers were mapped to 45 linkage groups representing all 21 wheat chromosomes. This map covered $3,885.1 \mathrm{cM}$ of total genetic distance, averaging $1.4 \mathrm{cM}$ between markers.

Four additive QTLs were detected on chromosomes 7DS, 3BS, 6AS, and 5AS (Table 3, Fig. 2), and these accounted for $60.0 \%$ of the total phenotypic variation in Stillwater and $59.4 \%$ in Lahoma. Additive effects of individual QTLs varied from 5.0 to $38.4 \%$ for leaf

Table 1. Comparison of seedling reactions to known rust races between parents and wheat lines with known resistance genes on chromosome arm 3BS

\begin{tabular}{llccc}
\hline & & \multicolumn{3}{c}{ Races $^{\mathbf{a}}$} \\
\cline { 3 - 5 } Wheat line & Known genes & BBBDB & MCDSB & PNMR \\
\hline Clark & $\ldots$ & $3+$ & $3+$ & $3 ;$ \\
Ning7840 & $\operatorname{Lr} 26$ & $; 1-$ & $3 ;$ & $; 1$ \\
Chinese Spring & $\operatorname{Lr} 12(=\operatorname{Lr} 31)$ & $3+$ & $3+$ & $3+$ \\
CS Hope 3B DS (TA3203) & $\operatorname{Lr} 27+\operatorname{Lr} 31$ & $; 3$ & $33+$ & $3+$ \\
\hline
\end{tabular}

${ }^{\mathrm{a}}$ For rust ratings, $0=$ no visible uredia, $1=$ hypersensitive flecks or small uredia with necrosis, 2 = small to medium sized uredia with green islands and surrounded by necrosis or chlorosis, $3=$ medium sized uredia with or without chlorosis, $4=$ large uredia without chlorosis, $1-=$ rating $>0$ and $<1$, and $3+=$ rating $>3$ and $<4$.

Table 2. Wheat leaf rust severity (\%) for Ning7840, Clark, and a recombinant inbred line (RIL) population evaluated in Stillwater and Lahoma, OK, in 2002

\begin{tabular}{lcccccc}
\hline & \multicolumn{2}{c}{ Parents } & & \multicolumn{3}{c}{ RIL population } \\
\cline { 2 - 3 } Environment & Ning7840 $^{\mathbf{a}}$ & Clark $^{\mathbf{a}}$ & & Mean $^{\mathbf{a}}$ & Maximum & Minimum \\
\hline Stillwater & $12.7 \pm 2.7$ & $46.0 \pm 3.7$ & & $45.8 \pm 27.7$ & 93.3 & 1.2 \\
Lahoma & $12.3 \pm 8.8$ & $24.3 \pm 3.0$ & & $53.5 \pm 32.5$ & 99.0 & 2.0 \\
\hline
\end{tabular}

a Mean \pm standard error. 
rust severity. Among these QTLs, QLr.hwwg-7DS, QLr.hwwg-3BS.1, and $Q L r . h w w g-6 A S$ were significant at both locations, whereas $Q L r$. $h w w g-5 A S$ was significant only at Lahoma. QLr.hwwg-7DS had the largest effect on leaf rust resistance, and was positioned at Lr34exon11$K A S P$ on the short arm of chromosome 7D, with the positive allele coming from Ning 7840. This QTL explained $38.4 \%$ and $31.7 \%$ of the phenotypic variance at Stillwater and Lahoma, respectively. The second most important QTL, QLr.hwwg-3BS.1, was located in the marker interval IWA4654 and IWA1702 on the short arm of chromosome 3B, and accounted for $19.2 \%$ and $16.6 \%$ of the phenotypic variance in the respective environments, with the resistance allele from Clark. $Q L r$. $h w w g-6 A S$ and $Q L r . h w w g-5 A S$ showed a minor effect on leaf rust severity. QLr.hwwg-6AS explained $5.0 \%$ and $7.1 \%$ of the phenotypic variance at Stillwater and Lahoma, respectively, with the Clark allele associated with decreased severity. QLr.hwwg-5AS accounted for $7.5 \%$ of the phenotypic variation with the positive allele from Ning7840.

Interaction between QTLs with major effects. To explore the interaction among the three QTLs (Lr34, QLr.hwwg-3BS.1, and $Q L r$. $h w w g-6 A S)$ that had significant effects in both locations, we calculated the group mean leaf rust severity of Ning $7840 \times$ Clark RILs with different QTL combinations. The RIL groups were identified by the markers Lr34exon11-KASP for Lr34, IWA1702 for QLr. $h w w g-3 B S .1$, and Xbarc23 for $Q L r . h w w g-6 A S$. The mean rust severity was the lowest for the genotypes with resistance alleles from all three QTLs and the highest for the genotypes with susceptible alleles at all three QTLs (Fig. 3). The Lr34 allele contributed by Ning7840 showed the largest additive effect on leaf rust resistance, and QLr.hwwg-3BS.1 had the second largest effect. The combination of $L r 34$ and $Q L r$. $h w w g-3 B S .1$ showed much lower rust severity than any other two-gene combinations.

\section{Discussion}

In previous studies, Chinese wheat cultivar Ning7840 was found to carry leaf rust QTLs Lr34 on 7DS and Qlr.pser.1BL, which was closely associated with a lesion mimic locus, $l m$, on $1 \mathrm{BL}$. Qlr.pser. $1 B L$ exhibited additive effects with $\operatorname{Lr} 34$ and was suggested to be a novel source of APR to leaf rust. In the current field study, QTL analysis confirmed that Ning7840 carries Lr34, which was the QTL with the largest and most consistent effect detected in the population. However, no QTL was detected on chromosome 1B in either field location. Therefore, we did not confirm that $l m$ is associated with resistance to leaf rust under field conditions. It is possible that expression of Qlr.pser. $1 B L$ is environmentally dependent. $L r 26$ is an all-stage resistance gene on the 1RS.1BL translocation in Ning7840 (Li and Bai 2009). The lack of detection of this gene in the field trials is probably due to the high frequency (35\%) of virulence to Lr26 in the Southern Great Plains in 2001 (Kolmer et al. 2003).

QLr.hwwg-5AS was the second QTL detected in Ning7840 and accounted for $7.5 \%$ of the phenotypic variation at Lahoma, but was not significant at Stillwater. The chromosomal location was similar to an APR gene on 5AS reported in European cultivar Beaver (Singh et al. 2009). However, QLr.hwwg-5AS was not detected in the previous greenhouse study ( $\mathrm{Li}$ et al. 2012) and therefore may be either environment-dependent or spurious.

The strongest QTL detected in cultivar Clark was QLr.hwwg$3 B S .1$, which was mapped on chromosome arm 3BS between markers IWA4654 and IWA1702 near Xgwm533. This is an important region that contains durable adult plant stem rust resistance gene $S r 2$ about $0.4 \mathrm{cM}$ distal to Xgwm533 and the Fusarium head blight major QTL Fhb1 about $2 \mathrm{cM}$ proximal (Zhang et al. 2016). $S r 2$ is tightly linked or it has a pleiotropic effect on resistance to leaf rust (designated Lr27) and yellow rust (Yr30) (Mago et al. 2011b; Singh et al. 2011). Using the $S r 2$ marker csSr2 (Mago et al. 2011a), Ning7840 and Clark both carried the marker allele associated with susceptibility (data not shown). $L r 27$ is a race-specific resistance gene that contributes to allstage resistance when it is present together with the complementary gene Lr31 on chromosome 4B (Nelson et al. 1997; Singh and McIntosh 1984). However, $L r 27+L r 31$ was ruled out in our seedling tests, which showed that $L r 14 a$ is likely the only all-stage resistance gene present in Clark. Since virulence to $L r 14 a$ was at $100 \%$ frequency in the field in the Southern Plains (Kolmer et al. 2003), it could not have contributed
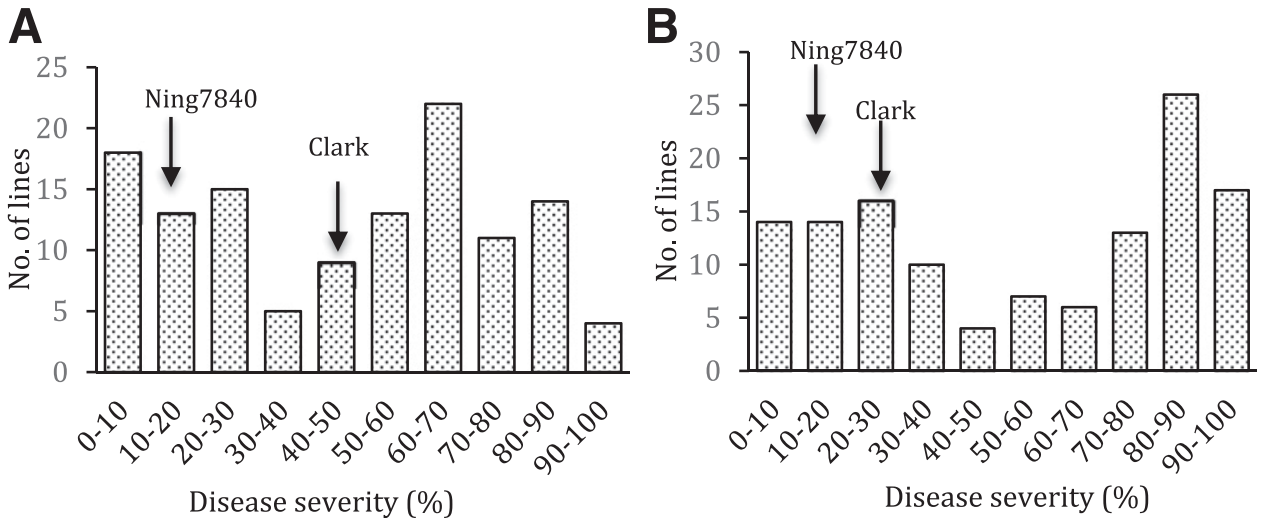

Fig. 1. Frequency distribution of leaf rust severity from Ning $7840 \times$ Clark RIL population evaluated in, A, Stillwater and, B, Lahoma. The values for the parents Ning7840 and Clark are indicated by arrows.

Table 3. Additive effects of QTLs on adult plant leaf rust resistance detected in Ning $7840 \times$ Clark population evaluated in Stillwater and Lahoma, OK, in 2002

\begin{tabular}{|c|c|c|c|c|c|c|c|c|c|}
\hline \multirow[b]{2}{*}{ QTL } & \multirow[b]{2}{*}{ Chr. } & \multirow[b]{2}{*}{ Marker interval } & \multirow[b]{2}{*}{ Interval in $\mathbf{c M}$} & \multicolumn{3}{|c|}{ Stillwater } & \multicolumn{3}{|c|}{ Lahoma } \\
\hline & & & & LOD $^{\mathbf{a}}$ & PVE $(\%)^{b}$ & $\overline{\text { ADD }^{\mathbf{c}}}$ & $\mathbf{L O D}^{\mathbf{a}}$ & PVE $(\%)^{b}$ & ADD \\
\hline QLr.hwwg-7DS & 7DS & Lr34exon11-KASP & N/A & 17.8 & 38.4 & -17.3 & 14.2 & 31.7 & -18.4 \\
\hline QLr.hwwr-3BS.1 & 3BS & IWA4654-IWA1702 & 0.5 & 10.8 & 19.2 & 12.1 & 9.5 & 16.6 & 13.2 \\
\hline QLr.hwwg-6AS & $6 \mathrm{AS}$ & Xbarc23-IWA3321 & 14.2 & 3.4 & 5.0 & 6.2 & 4.1 & 7.1 & 8.6 \\
\hline$Q L r . h w w g-5 A S$ & $5 \mathrm{AS}$ & IWA2145-IWA5053 & 7.4 & $\ldots$ & $\ldots$ & $\ldots$ & 4.4 & 7.5 & -8.8 \\
\hline Total & $\ldots$ & $\ldots$ & $\ldots$ & $\ldots$ & 60.0 & $\ldots$ & $\ldots$ & 59.4 & $\ldots$ \\
\hline
\end{tabular}

${ }^{a}$ LOD peak value at the center of the QTL.

${ }^{b}$ Percentage of phenotypic variation explained by the QTL.

${ }^{c}$ Additive effect. A negative additive effect value implies that the Ning7840 allele caused lower leaf rust severity (greater resistance), whereas the positive additive effect value implies that the Clark allele provided resistance. 
to resistance in the field. Therefore, QLr.hwwg-3BS.1 must be an APR gene.

There have been several other leaf rust APR QTLs reported on 3BS near Xgwm533. Leaf rust APR gene LrSV2 was described in cultivar Sinvalocho MA on 3BS. It was suggested to be allelic to $L r 27$ (Ingala et al. 2012). Recent fine mapping of the genes in the region demonstrated that both $S r 2$ and $L r S V 2 / L r 27$ were mapped in the same Ctg0011 contig (Diéguez et al. 2014; Mago et al. 2011b).
Buerstmayr et al. (2014) described a QTL for APR to leaf rust, designated QLr.ifa-3BS, in the cultivar Capo. It was mapped between markers Xbarc133 and Xgwm389, which spans the region around $X g w m 533$. Lu et al. (2017) described a minor adult plant leaf rust QTL, QLr.hwwg-3BS, in cultivar Lakin near Xgwm533. Recently, $\mathrm{Lr} 74$ was described in cultivar Spark as the first officially numbered leaf rust APR gene on 3BS (McIntosh et al. 2015). It was mapped approximately $5 \mathrm{cM}$ distal to $X g w m 533$, with the following marker
$5 \mathrm{~A}$

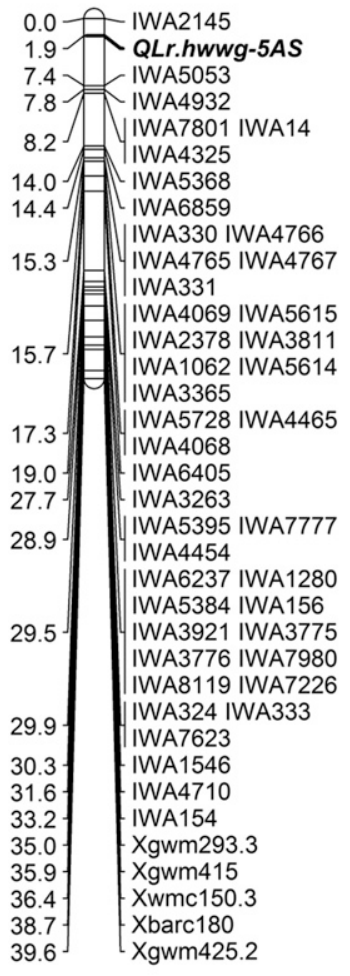

$6 \mathrm{~A}$

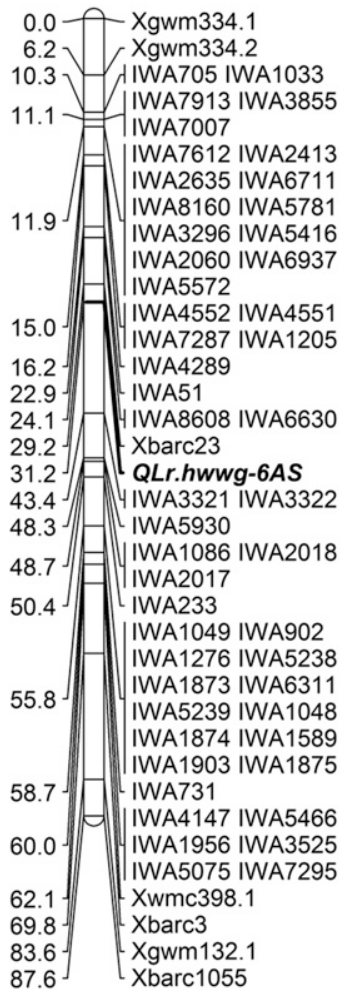

3B

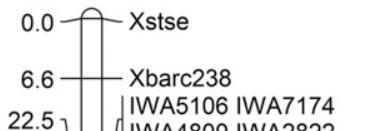

22.5 IWA4800 IWA2822

$23.0]$ IWA7230

23.8 |IWA6651 IWA3724

/IWA4654

24.0 QLr.hwwg-3BS.1

24.2 HIWA1702 IWA5203

H IIWA5202 IWA5201

24.6 H W IWA6471

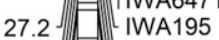

29.0 Xgwm389

31.3 $=$ Xstsp

33.6 [Xbarc147

36.2 Umn10

37.0 Xgwm533

40.1 -Xgwm493

43.3 U IWA7678 IWA3260

IIWA7231

44.1 $\left[\begin{array}{l}\text { IWA7363 } \\ \text { IWA715 }\end{array}\right.$

59.5 [Xbarc131
7D

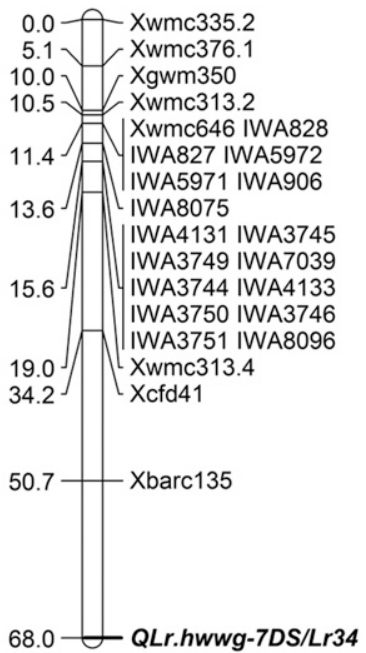

Fig. 2. QTLs associated with leaf rust resistance in the Ning7840 $\times$ Clark RIL population. The positions of marker loci are shown to the right of the linkage groups and centiMorgan (CM) distances between loci are shown on the left. QTLs are denoted in boldface italic type.

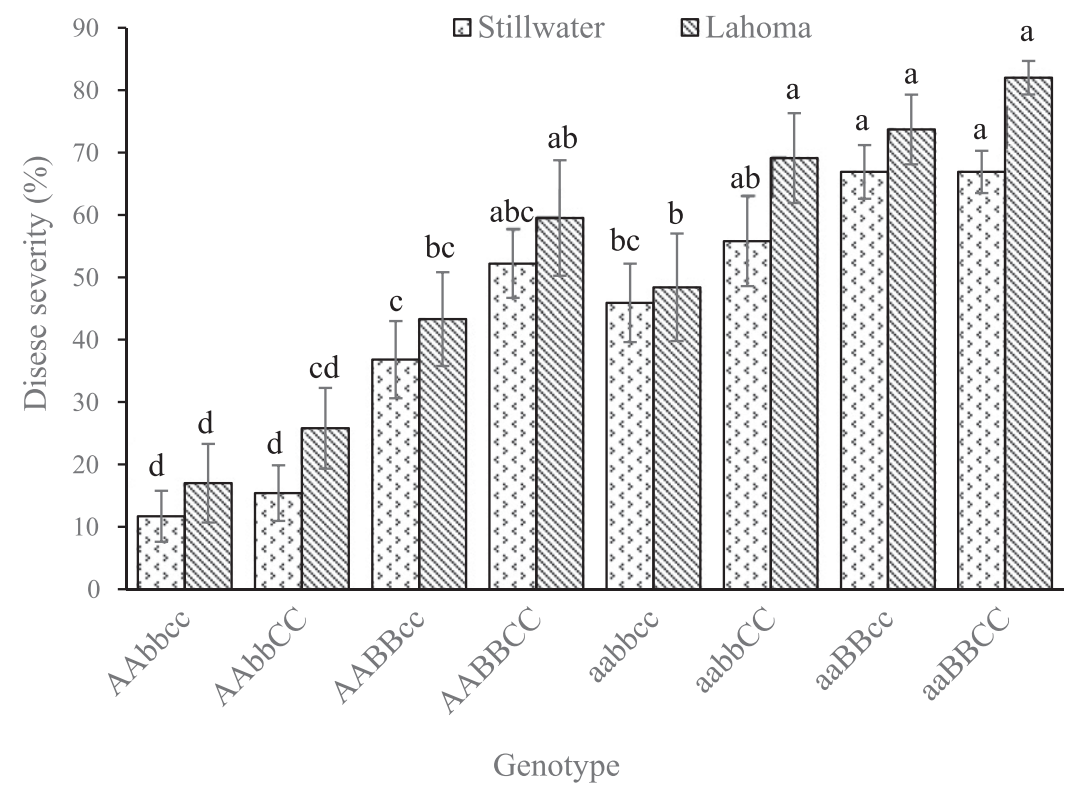

Fig. 3. Effect of Lr34 (AA) from Ning7840, QLr.hwwg-3BS.1 (bb), and QLr.hwwg-6AS (cc) from Clark on leaf rust severity in Stillwater and Lahoma, OK. AA indicated the leaf rust resistance allele from Ning7840 and bb and cc indicated the leaf rust resistance allele from Clark. Disease severities are expressed as mean percentage of rusted leaf area for each genotype group \pm standard errors. Different letters $(a, b, c, d)$ on the tops of standard error lines indicate the significant differences in rust severity among genotypes at a level of $5 \%$. 
order: Xcfb5006-3B - $1.9 \mathrm{cM}-L r 74-2.2 \mathrm{cM}-B S D 00009992-2.7$ cM - Xgwm533-3B (McIntosh et al. 2015). However, those marker distances do not agree with the fine mapping results of Diéguez et al. (2014) who found that Xcfb5006, which cosegregated with $L r S V 2$, was only $0.3 \mathrm{cM}$ distal to Xgwm533. Our genetic linkage map around $Q L r . h w w g-3 B S .1$ had some ambiguity in marker order, so we used POPSEQ (Edae et al. 2015) to locate the sequences of flanking markers IWA4654 and IWA1702 (Wang et al. 2014) as well as the sequence of $\mathrm{Xgwm533}$ (https://wheat.pw.usda.gov/cgi-bin/ GG3/report.cgi?class=probe;name=WMS533). All three were found in the same recombination bin in the W7984 genome assembly and spanned less than $1 \mathrm{cM}$ in the Chinese Spring Survey assembly. Therefore, leaf rust APR genes LrSV2, QLr.ifa-3BS, Lr74, QLr.hwwg-3BS, and $Q L r . h w w g-3 B S .1$ are all very close to $X g w m 533$ on $3 B S$ and may be identical or allelic. We provisionally identified $Q L r . h w w g-3 B S .1$ as $L r 74$, pending further characterization. It would be useful to further characterize the infection phenotype, and to test the race specificity of $Q L r . h w w g-3 B S .1$ to a diverse collection of isolates.

The identification of $Q L r . h w w g-3 B S .1$ in Clark is significant for several reasons. First, the resistance level was sufficient to be valuable in wheat breeding. In the current study, QLr.hwwg-3BS.1 accounted for a 12 to $13 \%$ reduction in leaf rust severity, which is about twothirds as much as the effect of Lr34 (Table 3). Second, QLr.hwwg$3 B S .1$ performs well in combinations. The combination of favorable alleles from all three QTLs provided the lowest disease severity and the Lr34+QLr.hwwg-3BS.1 combination was the next lowest (Fig. 3). Third, QLr.hwwg-3BS.1 could account for some of the unidentified APR in soft red winter wheat. Wamishe and Milus (2004) reported that $40 \%$ of soft red winter wheat cultivars in the eastern USA had APR that could not be attributed to $\operatorname{Lr} 12, \operatorname{Lr} 13$, or $\operatorname{Lr34}$. Fourth, in addition to SSR marker Xgwm533, SNP markers IWA4654, IWA1702, and many others are tightly linked to the QTL and could be easily adapted for highthroughput marker-assisted selection. It appears that QLr.hwwg-3BS.1 in Clark is in repulsion phase with the closely linked $S r 2$ locus. It would be interesting to determine if $Q L r . h w w g-3 B S .1$ and $S r 2$ can be linked in coupling phase as was done with $S r 2$ and $F h b 1$ (Zhang et al. 2016).

The second QTL in Clark was QLr.hwwg-6AS, which is a minor QTL that was detected in both environments and that mapped between markers Xbarc23 and IWA3321. This QTL resulted in a disease severity reduction of $7.1 \%$ for those progenies inheriting the resistance allele from Clark. Darino et al. (2015) identified eight SSR markers, including Xbarc3 and Xcfd190, linked to the racespecific APR gene $L r B P 3$ on the same chromosome arm. In our study, the SSR marker Xbarc23 flanking $Q L r . h w w g-6 A S$ was closely linked to Xcfd190 (Somers et al. 2004), thus making it plausible that this QTL is the same as $\operatorname{LrBP3}$. Confirmation will require further work.

In this study, we identified four QTLs for leaf rust resistance in the RIL population of Ning $7840 \times$ Clark. Three of them were detected in both environments. Only $Q L r . h w w g-5 A S$ was significant in a single environment (Lohome). This could be due to different compositions of rust races in the two locations. The four QTLs were dispersed between the two parents that were both moderately resistant, which explained transgressive segregations observed in the RIL population. However, majority of transgressive segregation being susceptible RILs was not expected. This might be partially contributed by underrating rust severity of two parents, or by intricate interactions among the genes from the two parents. Analysis of QTL interaction indicated an additive effect on rust resistance among these QTLs from the two parents. Significant additive effects of $L r 34$ with other genes have been reported previously (Ellis et al. 2014). Therefore, pyramiding Lr34 with the resistance QTLs from Clark can significantly enhance APR to leaf rust in wheat.

\section{Acknowledgments}

This is contribution number 17-193-J from the Kansas Agricultural Experiment Station. This project is partly funded by the National Research Initiative Competitive Grants 2011-68002-30029, 2017-67007-25939, and 2017-67007-25929 from the USDA National Institute of Food and Agriculture; and Science and Technology Innovation Team Plan (2014KCT-25) from Shannxi province, China. Authors thank Shiaoman Chao for performing the genotyping on wheat $9 \mathrm{~K}$ iSelect chips.
Mention of trade names or commercial products in this publication is solely for the purpose of providing specific information and does not imply recommendation or endorsement by the US Department of Agriculture. USDA is an equal opportunity provider and employer.

\section{Literature Cited}

Bai, G. H., Kolb, F. L., Shanner, G., and Domier, L. L. 1999. Amplified fragment length polymorphism markers linked to a major quantitative trait locus controlling scab resistance in wheat. J. Phytopathol. 89:343-348.

Bernardo, A., Wang, S., St. Amand, P., and Bai, G. 2015. Using next-generation sequencing for multiplexed trait-linked markers in wheat. PLoS One 10:e0143890.

Bolton, M. D., Kolmer, J. A., and Garvin, D. F. 2008. Wheat leaf rust caused by Puccinia triticina. Mol. Plant Pathol. 9:563-575.

Buerstmayr, M., Matiasch, L., Mascher, F., Vida, G., Ittu, M., Robert, O., Holdgate, S., Flath, K., Neumayer, A., and Buerstmayr, H. 2014. Mapping of quantitative adult plant field resistance to leaf rust and stripe rust in two European winter wheat populations reveals co-location of three QTLs conferring resistance to both rust pathogens. Theor. Appl. Genet. 127:2011-2028.

Carver, B. F., and Rayburn, A. L. 1994. Comparison of related wheat stocks possessing 1B or 1RS.1BL chromosomes: Agronomic performance. Crop Sci. 34:1505-1510.

Cavanagh, C., Chao, S., Wang, S., Huang, B. E., Stephen, S., Kiani, S., Forrest, K., Saintenac, C., Brown-Guedira, B., Akhunova, A., See, D., Bai, G. H., Pumphrey, M., Tomar, L., Wong, D., Kong, S., Reynolds, M., da Silva, M. L., Bockelman, H., Talbert, L., Anderson, J. A., Dreisigacker, S., Baenziger, S., Carter, A., Korzun, V., Morrell, P. L., Dubcovsky, J., Morell, M., Sorrells, M., Hayden, M., and Akhunov, E. 2013. Genome-wide comparative diversity uncovers multiple targets of selection for improvement in hexaploid wheat landraces and cultivars. Proc. Natl. Acad. Sci. 110:8057-8062.

Darino, M. A., Diéguez, M. J., Singh, D., Ingala, L. R., Pergolesi, M. F., Park, R. F., McIntosh, R. A., and Sacco, F. 2015. Detection and location of LrII and other leaf rust resistance genes in the durably resistant wheat cultivar Buck Poncho. Euphytica 206:135-147

Diéguez, M. J., Pergolesi, M. F., Velasquez, S. M., Ingala, L., López, M., Darino, M., Paux, E., Feuillet, C., and Sacco, F. 2014. Fine mapping of LrSV2, a racespecific adult plant leaf rust resistance gene on wheat chromosome 3BS. Theor. Appl. Genet. 127:1133-1141

Edae, E. A., Bowden, R. L., and Poland, J. 2015. Application of population sequencing (POPSEQ) for ordering and imputing genotyping-by-sequencing markers in hexaploid wheat. G3 (Bethesda) 5:2547-2553

Ellis, J. G., Lagudah, E. S., Spielmeyer, W., and Dodds, P. N. 2014. The past, present and future of breeding rust resistant wheat. Front. Plant Sci. 5:641-654

Feuillet, C., Travella, S., Stein, N., Albar, L., Nublat, A., and Keller, B. 2003. Mapbased isolation of the leaf rust disease resistance gene $\mathrm{Lr} 10$ from the hexaploid wheat (Triticum aestivum L.) genome. Proc. Natl. Acad. Sci. USA 100:15253-15258.

Fu, D., Uauy, C., Distelfeld, A., Blechl, A., Epstein, L., Chen, X., Sela, H., Fahima, T., and Dubcovsky, J. 2009. A kinase-START gene confers temperaturedependent resistance to wheat stripe rust. Science 323:1357-1360.

Herrera-Foessel, S. A., Singh, R. P., Huerta-Espino, J., Rosewarne, G. M. Periyannan, S. K., Viccars, L., Calvo-Salazar, V., Lan, C., and Lagudah, E. S 2012. Lr68: a new gene conferring slow rusting resistance to leaf rust in wheat. Theor. Appl. Genet. 124:1475-1486.

Huang, L., Brooks, S. A., Li, W., Fellers, J. P., Trick, H. N., and Gill, B. S. 2003 Map-based cloning of leaf rust resistance gene $L r 21$ from the large and polyploid genome of bread wheat. Genetics 164:655-664.

Ingala, L., Lopez, M., Darin, M., Pergolesi, M. F., Diéguez, M. J., and Sacco, F. 2012. Genetic analysis of leaf rust resistance genes and associated markers in the durable resistant wheat cultivar Sinvalocho MA. Theor. Appl. Genet. 124:1305-1314

Kolmer, J. A., and Hughes, M. E. 2016. Physiologic specialization of Puccinia triticina on wheat in the United States in 2014. Plant Dis. 100:1768-1773.

Kolmer, J. A., Long, D. L., Kosman, E., and Hughes, M. E. 2003. Physiologic specialization of Puccinia triticina on wheat in the United States in 2001. Plant Dis. 87:859-866.

Kosambi, D. 1943. The estimation of map distance from recombination values. Ann. Eugen. 12:172-175.

Krattinger, S. G., Lagudah, E. S., Spielmeyer, W., Singh, R. P., Huerta-Espino, J., McFadden, H., Bossolini, E., Selter, L. L., and Keller, B. 2009. A putative ABC transporter confers durable resistance to multiple fungal pathogens in wheat Science 323:1360-1363.

Kumar, P. V. 2014. Development of weather-based prediction models for leaf rust in wheat in the Indo-Gangetic plains of India. Eur. J. Plant Pathol. 140:429-440.

Li, C., Bai, G., Carver, B. F., Chao, S., and Wang, Z. H. 2016. Mapping quantitative trait loci for plant adaptation and morphology traits in wheat using single nucleotide polymorphisms. Euphytica 208:299-312.

Li, T., and Bai, G. H. 2009. Lesion mimic associates with adult plant resistance to leaf rust infection in wheat. Theor. Appl. Genet. 119:13-21.

Li, T., Bai, G. H., and Gu, S. L. 2012. A combination of leaf rust resistance gene Lr34 and lesion mimic gene $l m$ significantly enhances adult plant resistance to Puccinia triticina in wheat. Chin. Sci. Bull. 57:2113-2119.

Li, Z., Lan, C., He, Z., Singh, H. R., Rosewarne, G. M., Chen, X., and Xia, X. 2014. Overview and application of QTL for adult plant resistance to leaf rust and powdery mildew in wheat. Crop Sci. 54:1907-1925. 
Liu, S., Pumphrey, M. O., Gill, B. S., Trick, H. N., Zhang, J. X., Dolezel, J., Chalhoub, B., and Anderson, J. 2008. Toward positional cloning of Fhbl, a major QTL for Fusarium head blight resistance in wheat. Cereal Res. Commun. 36 (Suppl. 6):195-201.

Long, D. L., and Kolmer, J. A. 1989. A North American system of nomenclature for Puccinia recondita f.sp. tritici. Phytopathology 79:525-529.

Lu, Y., Bowden, R. L., Zhang, G., Xu, X., Fritz, A. K., and Bai, G. 2017. Quantitative trait loci for slow-rusting resistance to leaf 1 rust in doubled haploid wheat population CI13227 × Lakin. Phytopathology https://dx.doi. org/10.1094/PHYTO-09-16-0347-R

Mago, R., Brown-Guedira, G., Dreisigacker, S., Breen, J., Jin, Y., Singh, R., Appels, R., Lagudah, E., Ellis, J., and Spielmeyer, W. 2011a. An accurate DNA marker assay for stem rust resistance gene $S r 2$ in wheat. Theor. Appl. Genet. 122:735-744.

Mago, R., Tabe, L., McIntosh, R. A., Pretorius, Z., Kota, R., Paux, E., Wicker, T., Breen, J., Lagudah, E. S., Ellis, J. G., and Spielmeyer, W. 2011b. A multiple resistance locus on chromosome arm 3BS in wheat confers resistance to stem rust $(S r 2)$, leaf rust $(\operatorname{Lr} 27)$ and powdery mildew. Theor. Appl. Genet. 123: 615-623.

McGrann, G. R. D., Steed, A., Burt, C., Nicholson, P., and Brown, J. K. M. 2015. Differential effects of lesion mimic mutants in barley on disease development by facultative pathogens. J. Exp. Bot. 66:3417-3428.

McIntosh, R. A., Dubcovsky, J., Rogers, W. J., Morris, C., Appels, R., and Xia, X. 2015. Catalogue of gene symbols for wheat: 2015-2016 Supplement. Shared Info. on Genetic Resour., Nat. Inst. of Genetics., Japan. https://shigen.nig.ac. jp/wheat/komugi/genes/macgene/supplement2015.pdf

McIntosh, R. A., Wellings, C. R., and Park, R. F. 1995. Wheat Rusts: An Atlas of Resistance Genes. CSIRO Publ., Clayton, Australia.

Moore, J. W., Herrera-Foessel, S., Lan, C., Schnippenkoetter, W., Ayliffe, M., Huerta-Espino, J., Lillemo, M., Viccars, L., Milne, R., Periyannan, S., Kong, X., Spielmeyer, W., Talbot, M., Bariana, H., Patrick, W., Dodds, P., Singh, R., and Lagudah, E. 2015. A recently evolved hexose transporter variant confers resistance to multiple pathogens in wheat. Nat. Genet. 47:1494-1498.

Moschini, R. C., and Perez, B. A. 1999. Predicting wheat leaf rust severity using planting date, genetic resistance, and weather variables. Plant Dis. 83:381-384.

Nelson, J. C., Singh, R. P., Autrique, J. E., and Sorrells, M. E. 1997. Mapping genes conferring and suppressing leaf rust resistance in wheat. Crop Sci. 37: 1928-1935.

Ohm, H. W., Shaner, G., Forster, J. E., Patterson, F. L., and Buechley, G. 1988. Registration of 'Clark' wheat. Crop Sci. 28:1031.

Peterson, R. F., Campbell, A. B., and Hannah, A. E. 1948. A diagrammatic scale for estimating rust intensity on leaves and stems of cereals. Can. J. Res. 26(c): 496-500.
Rosewarne, G. M., Singh, R. P., Huerta-Espino, J., and Rebetzke, G. J. 2008 Quantitative trait loci for slow rusting resistance in wheat to leaf rust and stripe rust identified with multi-environment analysis. Theor. Appl. Genet. 116:1027-1034.

Singh, D., Simmonds, J., Park, P. F., Bariana, H. S., and Snape, J. W. 2009. Inheritance and QTL mapping of leaf rust resistance in the European winter wheat cultivar 'Beaver'. Euphytica 169:253-261.

Singh, R. P., Huerta-Espina, J., Bhavani, S., Herrera-Foessel, S. A., Singh, D., Singh, P. K., Velu, G., Mason, R. E., Jin, Y., Njau, P., and Crossa, J. 2011. Race non-specific resistance to rust diseases in CIMMYT spring wheats. Euphytica 179:175-186.

Singh, R. P., and McIntosh, R. A. 1984. Complementary genes for reaction to Puccinia recondita tritici in Triticum aestivum II. Cytogenetic studies. Can. J. Genet. Cytol. 26:736-742.

Singh, S., and Bowden, R. L. 2011. Molecular mapping of adult-plant race-specific leaf rust resistance gene $\mathrm{Lrl} 2$ in bread wheat. Mol. Breed. 28:137-142.

Somers, D. J., Isaac, P., and Edwards, K. 2004. A high-density microsatellite consensus map for bread wheat (Triticum aestivum L.). Theor. Appl. Genet. 109:1105-1114

Wamishe, Y. A., and Milus, E. A. 2004. Genes for adult-plant resistance to leaf rust in soft red winter wheat. Plant Dis. 88:1107-1114.

Wang, J. K., Li, H. H., Zhang, L. Y., and Meng, L. 2012. QTL IciMapping version 3.2. Qunatitative Genetics Group, Inst. of Crop Sci., Chinese Acad. of Agric. Sci., Beijing. http://www.isbreeding.net.

Wang, S., Wong, D., Forrest, K., Allen, A., Chao, S., Huang, B. E., Maccaferri, M., Salvi, S., Milner, S. G., Cattivelli, L., Mastrangelo, A. M., Whan, A., Stephen, S., Barker, G., Wieskeke, R., Plieske, J., International Wheat Genome Sequencing Consortium, Lilemo, M., Mather, D., Appels, R., Dolferus, R., Brown-Guedira, G., Korol, A., Akhunova, A. R., Feuillet, C., Salse, J., Morgante, M., Pozniak, C., Luo, M. C., Dvorak, J., Morell, M., Dubcovsky, J., Ganal, M., Tuberosa, R., Lawley, C., Mikoulitch, I., Cavanagh, C., Edwards, K. J., Hayden, M., Akhunov, E. 2014. Characterization of polyploid wheat genomic diversity using a high-density 90,000 single nucleotide polymorphism array. Plant Biotechnol. J. 12:787-796.

Wu, C., Bordeos, A., Madamba, M. R. S., Baraoidan, M., Ramos, M., Wang, G-L., Leach, J. E., and Leung, H. 2008. Rice lesion mimic mutants with enhanced resistance to diseases. Mol. Genet. Genomics 279:605-619.

Zhang, D., Bai, G., Zhu, C., Yu, J., and Carver, B. F. 2010. Genetic diversity, population structure, and linkage disequilibrium in U.S. elite winter wheat Plant Genome 3:117-127.

Zhang, X., Rouse, M. N., Nava, I. C., Jin, Y., and Anderson, J. A. 2016. Development and verification of wheat germplasm containing both $\mathrm{Sr} 2$ and Fhb1. Mol. Breed. 36:85. 